\title{
A revisão de vida como recurso terapêutico no processo de hospitalização
}

\section{The review of life as a therapeutic resource in the hospitalization process}

\author{
Beatriz Maciel Santos ${ }^{1}$, Edison Francisco da Silva $2^{2}$, Diego Saimon de Souza Abrantes $3^{*}$ \\ ${ }^{1}$ Acadêmica de psicologia do Instituto Macapaense do Melhor Ensino Superior. Macapá-AP Brasil. E-mail: beatrizmacielsantos@gmail.com \\ ${ }^{2}$ Acadêmico de psicologia do Instituto Macapaense do Melhor Ensino Superior. Macapá-AP Brasil. E-mail: edisonamapa@gmail.com \\ ${ }^{3}$ Psicólogo, Coach e Docente no Instituto Macapaense do Melhor Ensino Superior. Macapá-AP Brasil. E-mail: diego_saimon@hotmail.com \\ *Autor para correspondência
}

\author{
Palavras-chave \\ Despersonalização \\ Perda de Identidade \\ História de Vida
}

Esta pesquisa teve como objetivo apresentar o processo de Revisão de Vida (RV) como um novo recurso terapêutico em hospitais para promoção da melhora da saúde de pacientes hospitalizados, promovendo-se o embate com a despersonalização inerente a muitos ambientes hospitalares. Fez-se uma pesquisa bibliográfica, com artigos colhidos das redes científicas Lilacs, Scielo e Pepsic e dissertações publicadas nas bibliotecas digitais de universidades brasileiras, ambos tendo como descritores: psicologia hospitalar; perda de identidade; despersonalização; revisão de vida e memória autobiográfica. Como adendo, usou-se o método de análise de conteúdo para coletar, interpretar, analisar e relacionar os materiais encontrados. O processo de despersonalização é um fenômeno em que o paciente perde a sua identidade devido às condições do espaço hospitalar e o tratamento que lhe é disponibilizado. A RV, com sua técnica de resgate da história de vida do sujeito, pode e deve ser utilizada como fonte de valorização do indivíduo, trabalhando seus aspectos emocionais e subjetivos, facilitando o enfrentamento do adoecimento, sendo mais uma ferramenta de trabalho para os cuidados com a saúde do paciente hospitalizado, reforçando a promoção da sua identidade e dirimindo os efeitos da despersonalização.

\section{Keywords}

Depersonalization

Loss of identity

Life's history

The objective of this research was to present the Life Review (LR) process as a new therapeutic resource in hospitals to promote the improvement of the health of hospitalized patients, and also to confront the depersonalization inherent in many hospital settings. A bibliographical research was done, with articles collected from the scientific networks Lilacs, Scielo and Pepsic and dissertations published in the digital libraries of Brazilian universities, with the following descriptors: hospital psychology; loss of identity; depersonalization; life review and autobiographical memory; As an addendum, the content analysis method was used to collect, interpret, analyze and relate the found materials. The process of depersonalization is a phenomenon in which the patient loses his identity due to the conditions of the hospital space and the treatment that is available to him. The $L R$, with its technique of rescue of the life history of the subject, can and should be used as a source of valorization of the individual, working its emotional and subjective aspects, facilitating the confrontation of the illness, being another tool of work for the care with the hospitalized patient's health, reinforcing the promotion of their identity and denning the effects of depersonalization.

\section{INTRODUÇÃO}

Segundo Campos (1995) e Foucault (1979), a prática médica não era a principal ferramenta utilizada nos primeiros hospitais existentes, e sim a prática religiosa. Uma realidade difícil de imaginar, levando em consideração que, atualmente, a figura médica é vista como detentora de todo o conhecimento e poder nesses espaços, tendo a ciência que prevalecer diante do apregoado pela religião.

A transformação dos hospitais obteve diversos efeitos positivos, sendo o principal deles: a atenção especial e a cura de doenças dos pacientes. Mesmo com a atenção às doenças e com a finalidade de cura, observam-se aspectos que deixam de ser considerados na dinâmica hospitalar. São todas essas questões que são subjetivas dos pacientes. Isso resulta em uma perda de identidade, também chamada de despersonalização, em que as pessoas ficam tão envolvidas com seu adoecimento, seja por conta do ambiente restrito ou pelo tratamento, que deixam de se ver como seres humanos e passam a ver-se apenas como sua doença (CAMOM, 2010; IMANISHI; SILVA, 2016; MALDONADO; CANELA, 2003).

Deste modo, na busca por uma metodologia diferenciada e moderna, descobriu-se o método conhecido como Revisão de Vida (RV), muito utilizado como possibilidade de intervenção com idosos, como recurso terapêutico para dar voz ao paciente e escutá-lo para além de sua doença. Trata-se de um trabalho inovador e diferenciado em hospitais, e que ajuda na firmação da identidade perdida em decorrência do 
adoecimento. Com essa ideia em mente, desejou-se, através de um minucioso estudo bibliográfico, discutir a aplicabilidade da RV como método propício de melhorias na condição de saúde do paciente hospitalar, enfrentando-se o processo de despersonalização resultante, em muitos casos, da própria hospitalização.

\section{Despersonalização nos hospitais}

No processo de hospitalização, a despersonalização é entendida como um fenômeno em que o paciente perde a sua identidade devido as condições do espaço hospitalar, o tratamento que lhe é disponibilizado e a alienação perante ao seu adoecimento. Despersonalizar significa perder ou mudar a personalidade e a identidade (AULETE, 2004).

Maldonado e Canela (2003), bem como Imanishi e Silva (2016), destacam alguns aspectos relacionados ao tratamento e as condições hospitalares que contribuem para a perda de identidade dos pacientes, sendo eles: o fato de o hospital ser um ambiente restrito que tem como foco a doença; o autoritarismo do local e a adaptação dos pacientes às regras que Ihe são impostas; o tratamento dado pela equipe, que vive em condições de estresse por inúmeros motivos como pressão, rotina intensa e salários baixos ou atrasados; e a equipe multidisciplinar que, muitas vezes, não funciona como deveria, sem haver comunicação eficiente entre os diversos profissionais para uma melhor compreensão acerca do paciente. Ou seja, percebe-se como a dinâmica hospitalar é "despersonalizante".

De acordo Camom (2010), a pessoa deixa de ser reconhecida como ela mesma e passa a ser sua patologia ou seu número de leito. De repente, é como se o seu diagnóstico a definisse e ela não tivesse mais escolhas, cabendo ao saber médico definir sua vida. Portanto, entende-se que ter como finalidade o tratamento da doença orgânica, enumerar as pessoas por leitos e reconhecê-los a partir disso trata-se de uma questão de dinâmica e organização hospitalar. Contudo, é importante pensar nos efeitos emocionais que estas condições podem provocar, atrasando ou dificultando o processo de cura ou tratamento. Uma maneira de mudar tal condição pode ser o uso da RV que, diante do fenômeno da despersonalização, mostra-se como uma importante técnica de resgate de identidade e autoconhecimento.

\section{O processo de revisão de vida}

Robert Neil Butler (1927-2010), ao dedicar-se a estudos direcionados a gerontologia, foi o precursor do método conhecido como RV. Trata-se de um processo de retorno a vivências passadas, que pode propiciar resolução de conflitos interiores, aceitação do presente, alívio de sentimentos negativos, autoconhecimento e identificação do sentido da vida (LEÃO, 2005; SALVADO, 2013).

Perez e Almeida (2010), assim como outros autores brasileiros (LEÃO, 2005; SALVADO, 2013), utilizaram a RV como instrumento de intervenção terapêutica. O método é, de certo modo, simples de ser executado, exigindo domínio emocional do terapeuta. Dá-se espaço para que o paciente discurse sobre sua história de vida, promovendo assim o acesso às memórias passadas que acionadas, podem propiciar um sentimento de bem-estar e permitir a resolução de conflitos emocionais inerentes a essa rememoração.

Ao trabalhar este método com um grupo de idosos em Terapia Ocupacional, os autores supracitados obtiveram as seguintes conclusões: a verbalização de histórias de vida é significativa não apenas para aqueles que falam, mas também para os que escutam, pois enriquece a experiência dos envolvidos; a atividade proposta possibilita o resgate de lembranças e reflexões acerca da fase atual da vida; necessidades e desejos dos indivíduos são identificados, o que os ajuda a ampliar as concepções sobre si mesmos.

\section{METODOLOGIA}

Este estudo caracteriza-se como uma pesquisa bibliográfica, definida por Gil (2008) como um trabalho científico que é desenvolvido a partir de materiais já elaborados por outros pesquisadores. Para a exploração, organização, análise e interpretação desses materiais, usouse a Análise de Conteúdo que é dividida em cinco passos, conforme Moraes (1999):

1. Preparação: consistiu em identificar as informações que foram analisadas. Para isso, foram acessados artigos nas plataformas digitais Lilacs, Pepsic e Scielo, além de dissertações de mestrado de instituições públicas e privadas do Brasil. Cada bibliografia tinha que apresentar pelo menos uma das seguintes palavras-chave: psicologia hospitalar; perda de identidade; despersonalização; revisão de vida e memória autobiográfica. Foram feitas as leituras dos resumos dos materiais encontrados e assim selecionaram-se os que atendiam aos objetivos dos pesquisadores.

Ressalta-se que não se estabeleceu critérios temporais e quantitativos para as publicações, devido à novidade do tema trabalhado, pois ele foi pouco explorado na literatura científica até então e não se desejou limitar o acesso às bibliografias, fosse por questão do período de publicação ou das quantidades a serem analisadas neste estudo.

Nas redes Pepsic e Scielo, a expressão "revisão de vida", quando pesquisada em Dezembro de 2018, obteve resultado igual a zero de obras indexadas. Na rede Lilacs, obteve-se 17 obras no Brasil, sendo a maior parte de temas sem conexão 
factual com a proposta deste estudo. Assim, vários dos conteúdos aqui analisados advieram do uso das outras palavras-chaves dentro dos indexadores já citados: psicologia hospitalar; perda de identidade; despersonalização; e memória autobiográfica. Para ultrapassar tal dificuldade de acesso à literatura nacional, considerou-se publicações em língua estrangeira, com a tradução do descritor "Revisão de Vida" para a língua inglesa, "Review of life". Encontrou-se apenas duas obras. Deste modo, obteve-se um total de dezenove obras analisadas.

2. Unitarização: depois de selecionados, leu-se cuidadosamente os materiais que foram categorizados em unidades cujos conteúdos assemelhavam-se.

3. Categorização: se fez o agrupamento dos materiais semelhantes de maneira mais profunda, considerando todo o conteúdo dissertado nele, podendo-se definir, com isso, dois grupos de análise: "Despersonalização" e "Revisão de Vida".

4. Descrição: foram produzidos textos sínteses dos conteúdos obtidos, isto é, resumos dos materiais selecionados.

5. Interpretação dos estudos: analisou-se profundamente os conteúdos pesquisados. A partir disso, com os dados interpretados, foi realizada a avaliação crítica dos resultados e estabelecida relação entre os elementos encontrados.

Vale ressaltar que esta pesquisa resulta de um estudo maior realizado pelo trio de pesquisadores em 2018.

\section{RESULTADOS}

De acordo com a análise das bibliografias, o processo terapêutico da RV é utilizado por vários autores (LEWIS, 1971; BUTLER, 1974; MOLINARI; REICHLIN, 1985; LEÃO, 2005; PEREZ; ALMEIDA, 2010; SALVADO, 2013) como forma de extrair memórias adquiridas ao longo da vida, com o objetivo de facilitar o autoconhecimento, melhorar o entendimento do estado atual da pessoa e consequentemente a resolução de conflitos. Geralmente é utilizado em idosos, devido a carga de experiências vividas e pode ser realizado de diversas maneiras, como através de dinâmicas e verbalização livre (LEÃO, 2005) ou através de entrevistas (SALVADO, 2013).

Salvado (2013) utilizou entrevistas que envolviam perguntas direcionadas a todas as fases da vida. A autora buscou captar as experiências mais marcantes dos participantes. Assim, ela concluiu que é importante o terapeuta estar preparado para escutar temas delicados e respeitar as pausas e silêncios, que podem acontecer proveniente da emoção. É fundamental o estabelecimento de rapport, isto é, da relação de confiança paciente-profissional, para que o participante tenha confiança e vontade de contar sua trajetória de vida.
Apresenta-se a RV como uma possibilidade de atuação em hospitais, pois como destacam Maldonado e Canela (2003), Camom (2010), Imanishi e Silva (2016), estes ambientes têm como foco tratar o adoecimento orgânico e seus sintomas, entretanto, são instituições restritas e autoritárias, muitas vezes com atendimento inadequado por parte da equipe, tendo o sistema de trabalho multidisciplinar falho. Tudo isso acarreta na despersonalização do sujeito.

Assim, utilizando a RV como instrumento terapêutico nos hospitais, o foco é o paciente, ou seja, o ser humano, e não sua doença. Trata-se de um atendimento diferenciado, não impositivo, em que o paciente tem autonomia sobre quem é e tem a oportunidade de maior interação com a equipe de saúde que cuida dele, sendo mais condizente as proposições de tratamento. Ele conta sobre si e relembra suas histórias, enquanto o psicólogo, enfermeiro, médico, terapeuta ocupacional, o escuta.

Para que o efeito terapêutico ocorra é preciso respeitar a fala, mas também o silêncio, sendo o maior objetivo possibilitar que a pessoa entre em contato com seu passado, de modo que isso resulte em uma melhora no seu momento atual. Esta melhora está ligada, sobretudo, ao autoconhecimento, pois o ato de verbalizar sua história faz com que o indivíduo conheça a si próprio. Ele sai do processo de despersonalização para o processo de reforço da autoidentidade, para uma "personalização". Isso tende a melhorar sua autoestima e autoconfiança devido a consequente autoafirmação de sua identidade.

Assim, ao rememorar os feitos de sua vida, o paciente reflete sobre sua própria história, conquistas, perdas, alegrias, tristezas. Esse processo reflexivo tende a fazê-lo entender melhor, inclusive, os fatores de risco que o levaram a doença que o deixa acamado naquele momento. Geralmente, assim, ele encontra motivação para enfrentar a patologia que o acomete, sendo mais receptivo ao tratamento (LEÃO, 2005; BRANDÃO, 2008; PEREZ; ALMEIDA, 2010; SALVADO, 2013).

Resgata-se a ideia de que a RV não tem um único padrão de aplicação. Ela pode ser adaptada a cada espaço hospitalar e isso é uma necessidade, pois analisando os escritos de Cabral, Amaral e Brandão (2009), valorizando o ser humano enfermo e dirimindo o sofrimento que ele sente ao estar na situação em que se encontra, é possível promover a melhoria contínua da saúde do paciente. Essa situação varia de ambiente hospitalar para ambiente hospitalar assim como de contexto a contexto. Em algumas ocasiões, talvez o paciente tenha dificuldades para verbalizar oralmente. Nesse caso, por exemplo, pode ser interessante deixá-lo escrever sua história de vida. Essa escrita pode ser com caneta e papel ou digitado no celular ou notebook. São adaptações necessárias a se tomar pela equipe de saúde para que a técnica não deixe de ser aplicada, pois o efeito terapêutico é promovido, 
especialmente, através do processo de preparo do relato, que o induz a autorreflexão, e do compartilhamento desse relato, que o induz a expressar o que descobriu sobre si mesmo e estabelecer o que fazer, como se dedicar ainda mais ao tratamento ou que metas buscar ao sair do hospital. De todo modo, o sentimento de autoconfiança e autoestima gerados na $\mathrm{RV}$, e o desejo de reviver algo que já o fez, de resolver problemas não resolvidos, encontrar pessoas amadas, fazer o que nunca fez, leva o paciente a se motivar para superar a doença. Isso facilita todo o tratamento.

Seguindo esta linha de pensamento, de um lado há a hospitalização, um processo doloroso com potencial de despersonalização da pessoa (MALDONADO; CANELA, 2003; CAMOM, 2010; IMANISHI; SILVA, 2016), e do outro lado há a possibilidade de uso da RV e todos seus benefícios já descobertos, ressaltando a facilidade de aplicação no espaço hospitalar devido ao baixo ou zero custo financeiro (LEWIS, 1971; BUTLER, 1974; MOLINARI; REICHLIN, 1985; LEÃO, 2005; PEREZ; ALMEIDA, 2010; SALVADO, 2013).

Portanto, a RV tende a ser um processo estruturado de lembranças e de ressignificação, enfrentando-se a despersonalização dentro do ambiente hospitalar. A verbalização das histórias de vida proporciona o enriquecimento dos envolvidos e as atividades propostas possibilitam o resgate de reflexões acerca do adoecimento que é a fase atual de sua vida, permitindo a identificação dos desejos latentes do momento. Ela ajuda a ampliar a concepção que o paciente tem dele mesmo (LEÃO, 2005; PEREZ E ALMEIDA, 2010; SALVADO, 2013).

Trata-se de um processo estruturado e profundo, no qual lembrar não é o bastante (BRANDÃO, 2008; CABRAL; AMARAL; BRANDÃO, 2009). O indivíduo tenta entender o sentido daquilo que passou, mas que ainda está em sua memória. Ele recorre aos acontecimentos alegres e satisfatórios e também aos que Ihe provocaram tristezas, conflitos ou fracassos. Ele relembra de questões que podem ser contraditórias e as torna mais claras, ressignificando aquilo que é necessário. Nesse sentido, Brandão (2008), demonstra que ressignificar trata-se de um processo de atualizar histórias, no qual o sujeito ao relembrar, constrói outras percepções acerca de suas vivências, atribuindo novos significados a elas e, ao mesmo tempo, redefinindo seu lugar social e suas relações, possibilitando também um processo de autoconhecimento.

Deste modo, este método caracteriza-se como uma possibilidade de intervenção em hospitais, visto que, devido ao fenômeno da despersonalização, os pacientes passam a se ver e serem vistos apenas como a sua doença. A partir do momento em que se é dado voz ao paciente, ele fala, compartilha suas vivências, verbaliza sua história e pode ser representado por si mesmo. Ter alguém disposto a escutá-lo faz com que ele se sinta importante e perceba que sua história não é em vão, e o resgate dela vai muito além de lembrar e ressignificar, trata-se de uma firmação de sua identidade.

\section{CONSIDERAÇÕES FINAIS}

A carência de um tratamento mais humanizado, de alguém que se importe com a história de vida do paciente além de sua doença, favorece a despersonalização no ambiente hospitalar. As dificuldades próprias desse local, principalmente em instituições públicas, por exemplo, quando os pacientes não saem do hospital com receio de perder sua vaga na fila de cirurgias, limita o processo de cura da pessoa ao número de seu leito ou sua enfermaria, sendo esses os espaços que os doentes ocupam. O hospital tem como objetivo tratar o adoecimento orgânico e seus sintomas, sendo os aspectos subjetivos, sociais e culturais ignorados em muitos casos. Em suma, ignora-se a subjetividade humana em detrimento da doença.

A RV funciona como processo inverso à despersonalização ocorrida em pacientes hospitalizados, podendo ser aplicada nos hospitais, pois não se trata apenas de um local físico, mas de um espaço de caráter interativo que proporciona uma abertura para o ouvir e contar histórias de vida, provocando uma ampliação na percepção que o paciente tem de si próprio.

$\mathrm{Na}$ busca por literatura sobre o tema RV, percebeu-se que ainda são poucas as publicações com esta temática específica, fazendo deste estudo um adendo a esse arcabouço teórico ainda pobre. Realmente, houveram dificuldades em se encontrar literatura específica sobre o tema, mesmo tendo sido até considerados produções científicas estrangeiras. Apesar disso, foi possível confirmar, com as bibliografias analisadas, que ao revisar as próprias histórias de vida, as pessoas passam por um processo de autoconhecimento, gerando efeito oposto à despersonalização.

$E$, mesmo que essas literaturas sobre o tema estejam voltadas para a aplicação da RV na fase do envelhecimento, acredita-se que tal método de intervenção pode ser aplicada com pacientes hospitalares de diversas faixas etárias, como ferramenta de resgate da identidade perdida no processo de adoecimento e hospitalização.

Expor isso pode tornar seu uso cada vez mais popular e pragmático dentro dos ambientes hospitalares, tornando a RV mais uma opção, pautada na ciência, para o tratamento terapêutico de pacientes hospitalizados.

\section{REFERÊNCIAS}

AULETE, C. Minidicionário contemporâneo da língua 
portuguesa. Rio de Janeiro: Nova Fronteira, 2004. p.264.

BRANDÃO, V. M. A. T. Memória (auto)biográfica como prática de formação. Revista @mbiente educação, São Paulo, v. 1, n.1, jan./jul. 2008.

BUTLER, R.N. Successful aging and the role of the life review. Journal of the American Geriatrics Society, v. 22, 1974.

CABRAL, P.; AMARAL, R.; BRANDÃO, V. Oficinas de Memória Autobiográfica. Conversando com idosos: o registro das memórias vivas. Revista Kairós, São Paulo, v. 12, n. 1, p. 257-274, jan. 2009.

CAMOM, V. A. A. (org.). Psicologia Hospitalar: teoria e prática.

2. ed. São Paulo: Cengage Learning, 2010.

CAMPOS, T. C. P. Psicologia Hospitalar: A atuação de psicólogos em hospitais. São Paulo: EPU, 1995.

FOUCAULT, M. O Nascimento do Hospital. In: FOUCAULT, Michel. Microfísica do Poder. 20 ed. Rio de Janeiro: Graal, 1979.

GIL, A. C. Métodos e Técnicas de Pesquisa Social. 6 ed. São Paulo: Atlas, 2008.

IMANISHI, H. A.; SILVA, L. L. da. Despersonalização nos hospitais: o estádio do espelho como operador teórico. Revista SBPH, Rio de Janeiro, v. 19, n.1, p. 41-56, 2016.

LEÃO, M. A. B. G. Oficina de revisão de vida e bem-estar subjetivo em mulheres idosas: um estudo sobre um método de intervenção psicológica. Campinas: 2005.

LEWIS, C. Reminiscing and self-concept in old age. Journal of Gerontology, v. 26, 1971.

MALDONADO, M. T.; CANELLA, P. Recursos de relacionamento para profissionais de saúde: A boa comunicação com clientes e seus familiares em consultórios, ambulatórios e hospitais. São Paulo: Novo Conceito, 2003.

MOLINARI, V.; REICHLIN, R.E. Life review and reminiscence in the elderly: a review literature. International Journal of Aging and Human Development, v. 20, p. 81-92,1985.

MORAES, R. Análise de conteúdo. Revista Educação, Porto Alegre, v. 22, n. 37, p. 7-32, 1999.

PEREZ, M. P.; ALMEIDA, M. H. M. O processo de revisão de vida em grupo como recurso terapêutico para idosos em Terapia Ocupacional. Revista de Terapia Ocupacional da Universidade de São Paulo, São Paulo, v. 21, n. 3, p. 223229, set./dez. 2010.

SALVADO, S. C. de S. e C. Bem-estar no envelhecimento: a influência da Revisão do Percurso de Vida e do Storytelling. Faculdade de Ciências Humanas: 2013. 